\title{
Percent Change From Nadir
}

National Cancer Institute

\section{Source}

National Cancer Institute. Percent Change From Nadir. NCI Thesaurus. Code C96622.

The value of the last measurement taken divided by the lowest value recorded. 